CBIE-LACLO 2015

Anais dos Workshops do IV Congresso Brasileiro de Informática na Educação (CBIE 2015)

\title{
Introdução aos Estudos Virtuais
}

\author{
Vitor C. S. Valadares', Marta R. Bez ${ }^{1}$, André B. Trombetta1, Guilherme T. \\ Schneider ${ }^{1}$, João B. Mossmann'1, Richard N. Silva' ${ }^{1}$, Thiago G. Mendes', \\ ${ }^{1}$ LOA - Laboratório de Objetos de Aprendizagem - Universidade Feevale \\ ERS 239, 2755 - 93.600-000 - Novo Hamburgo - RS - Brasil \\ \{vitorvaladaresbr, martabez, gtschneider, trombetta, mossmann, \\ richard.n.silva\}@gmail.com, thiagogmefeevale.br
}

\begin{abstract}
This paper describes the development process of the Digital Learning Construct called "Introdução aos Estudos Virtuais". This is a software available to University students of distance-learning courses from the institution. It has been in use for two years, showing satisfactory results in terms of acceptance by students that made use of it as the first task from their courses.
\end{abstract}

Resumo. Este artigo apresenta o processo de desenvolvimento do Construto Digital de Aprendizagem (CDA) "Introdução aos Estudos Virtuais". Este é um software disponibilizado aos alunos de uma Instituição de Ensino Superior brasileira que possui cursos de graduação a distância. Está em uso a dois anos, apresentando resultados satisfatórios em termos de aceitação por parte dos alunos que o utilizam durante a primeira tarefa dos cursos.

\section{Introdução}

O CDA "Introdução aos estudos Virtuais" foi desenvolvido no Laboratório de Objetos de Aprendizagem e tem por objetivo orientar o usuário sobre os papéis desempenhados pelo professor, pelo tutor e, sobretudo, pelo aluno de EaD. Foi projetado para ser utilizado no ensino superior, para todos os cursos a distância da Universidade Feevale.

Todos os personagens do jogo são robôs cuja estética foi inspirada no filme "Wall-E". Espera-se que, com o uso do construto em questão, o aluno construa conhecimento interagindo com professores, tutores, e demais colegas, assim como com o próprio ambiente, desenvolvendo autonomia e realizando descobertas. Portante, busca-se que, a partir da experimentação deste CDA, os alunos de EaD no ambiente virtual troquem ideias e questionamentos, construam conhecimento, resolvam problemas de forma coletiva e individual, buscando organização e comprometimento.

\section{Desenvolvimento}

O CDA "Introdução aos Estudos Virtuais" foi construído a partir de uma estrutura não hierárquica (Bez et al., 2012), unindo esforços das quatro áreas: educação, comunicação, design e informática. Em Valadares (2014) é apresentada a metodologia utilizada no desenvolvimento do CDA.

Foram realizadas reuniões semanais com o setor de Núcleo de Educação a Distância (NEAD) da Universidade Feevale, onde conteudistas apresentavam os materiais a serem abordados no CDA e as características específicas de um ensino a 
distância. A partir disso chegou-se em um CDA que se passa em um conjunto de ilhas flutuantes, nas quais estão distribuídos diferentes tipos de missões para o jogador cumprir. $\mathrm{O}$ construto dá ao jogador o controle de um robô, e a câmera de jogo é configurada para uma visão em terceira pessoa

A definição do escopo e do cronograma foi discutida com todos os envolvidos, sendo apresentados em diversas reuniões ao NEAD para aprovação e definição dos papeis a serem desempenhados pela equipe na etapa de produção. Foi durante o decorre desta fase em que se definiu o conteúdo e realizaram-se os estudos para busca de referências para a estética e jogabilidade.

Numa etapa de pré-produção, foram definidos e, posteriormente, aprovados com as equipes a prototipagem e os concepts para o CDA. Para isso estipulou-se que o mesmo deveria ser composto por uma sequência pré-determinada de missões, nas quais haveria a necessidade do aluno resolver problemas para seguir adiante no CDA.

Foi criado um roteiro de missões que continham o conteúdo instrucional através da narrativa do ambiente. Para compor este conteúdo, desenhou-se um universo para o CDA na qual haveriam cinco ilhas, cada qual com suas missões, tutoriais, quando há necessidade, e filmes. A mecânica das missões foi dividida entre a busca por materiais pedagógicos sobre o tema, perguntas a serem respondidas e contatos com outros personagens do CDA, como, por exemplo, o professor, o tutor e os colegas.

Depois da definição das mecânicas básicas de jogabilidade e do conteúdo a ser apresentado ao usuário, criou-se um protótipo blocado do que viria a ser o construto. Este protótipo já contemplava o roteiro previamente estabelecido, assim como o fluxo de jogo pensado para as fases. Tanto o protótipo citado, quanto as demais versões do projeto foram construídas utilizando-se a game engine Unity.

Tendo-se finalizado o protótipo, foi realizada uma primeira validação do jogo. Foram convidadas cinco pessoas, com idades que variaram de 16 até 64 anos, para testar o objeto desenvolvido até então. No local onde os testes foram realizados, instalou-se o CDA em um único computador, de forma que cada teste era feito individualmente e de forma que as demais pessoas não pudessem ver o jogo até a sua vez de utilizá-lo. Além disso, foram instaladas duas câmeras, uma para capturar a tela do computador e outra para registrar as reações do usuário (Figura 1), assim como um microfone para gravar seus comentários. A técnica utilizada para validação foi Think-Aloud (ERICSSON, 1993) Todos os experimentos foram acompanhados por ao menos um conhecedor do CDA para esclarecimento de dúvidas e um observador, que acompanhava as reações do usuário e anotava aspectos que considerava importantes. Todos usuários chegaram até o final do experimento, tendo-se registrado um tempo médio de 21 minutos para isso. 


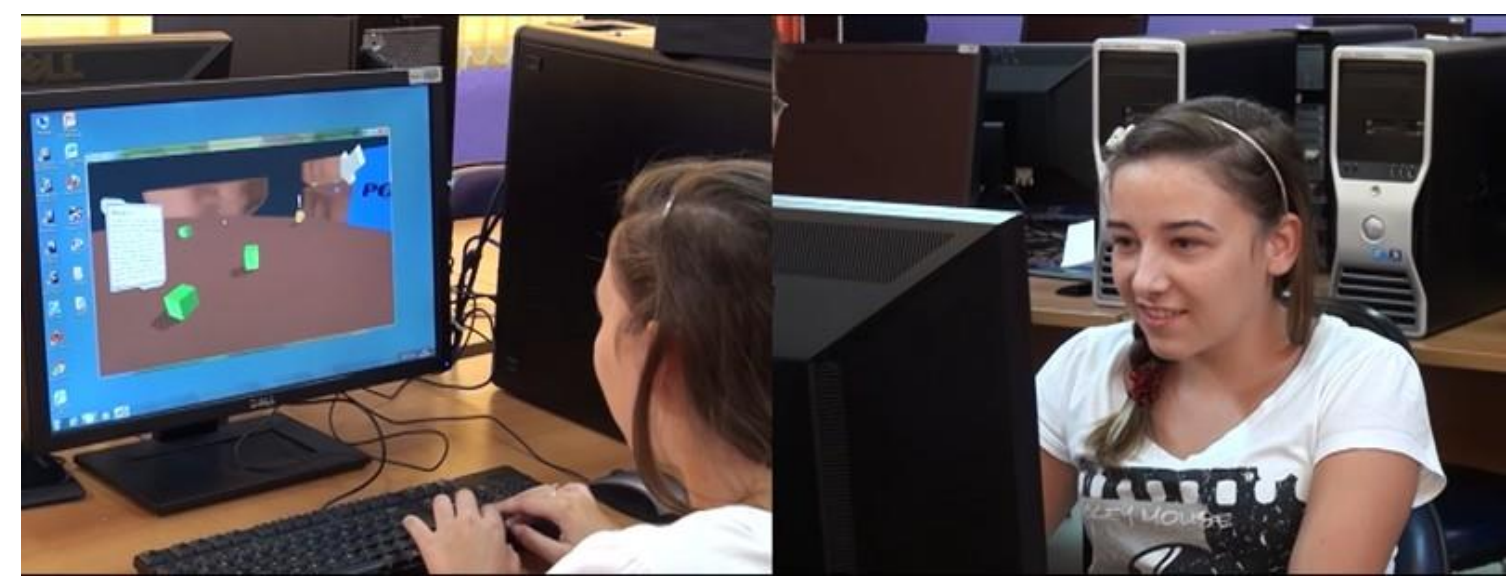

Figura 1. Validação do protótipo.

Diversos tipos de ajustes foram realizados no protótipo, tendo como base a avaliação realizada, visando sempre sanar as dificuldades e críticas observadas pelo grupo de teste. Foi também durante esta etapa que o projeto passou a contar com um aspecto mais acabado, já visando o que viria a ser o resultado final. Durante todo o período de produção, os representantes de cada área de conhecimento envolvida participaram de pelo menos uma reunião semanal do grupo.

Uma segunda fase de validação ocorreu após dois meses da primeira, agora com o produto pronto. Foi utilizado novamente o método de Think-Aloud, com duas câmeras e um microfone, e contando com a participação dos mesmos usuários. O objetivo desta validação foi verificar se as dúvidas, necessidades e dificuldades apontadas pelos usuários na primeira fase de pré-testes, bem como as sugestões, haviam sido resolvidas na versão final do CDA e se este ainda apresentava algum tipo de inconsistência. A Figura 2 apresenta uma aluna testando o CDA final.

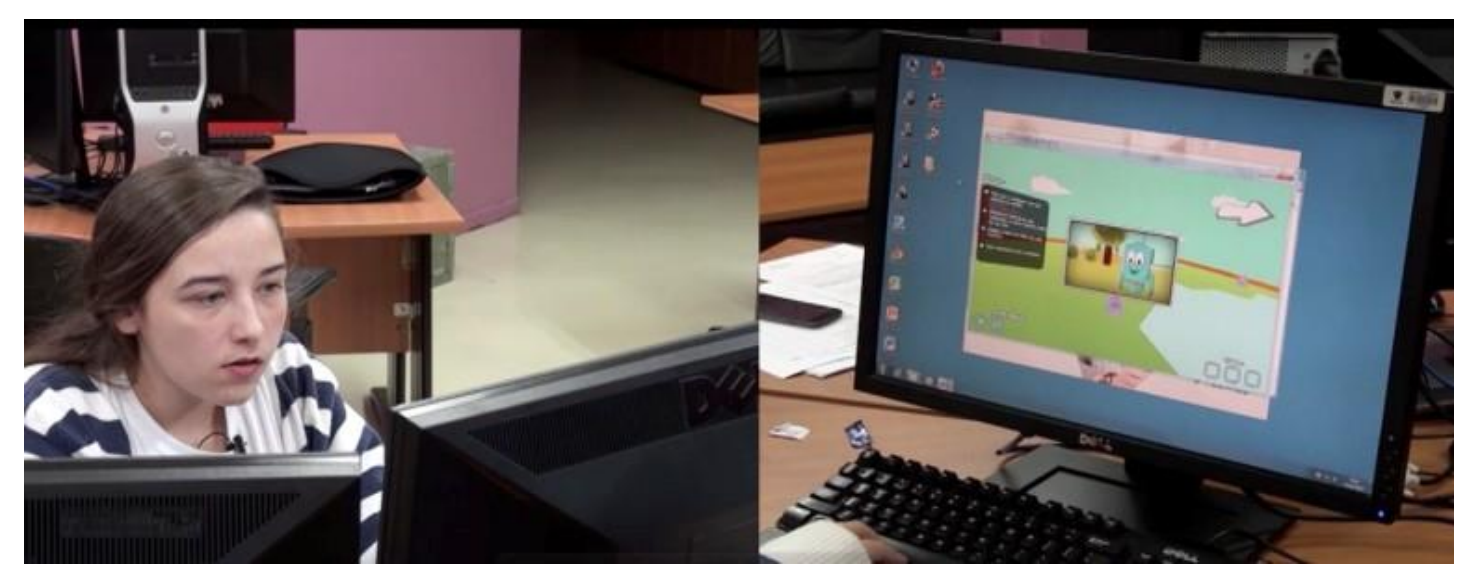

Figura 2. Validação do CDA na sua versão final.

Na próxima seção é apresentado o CDA desenvolvido e suas principais telas. Também pode ser visto o link para acesso ao CDA e o link do vídeo demonstrativo. 
CBIE-LACLO 2015

Anais dos Workshops do IV Congresso Brasileiro de Informática na Educação (CBIE 2015)

\section{Apresentação do software}

O CDA "Introdução aos Estudos Virtuais" possui cinco ilhas, contendo em cada uma das diversas missões, tutoriais e filmes. As tarefas passadas ao jogador em cada ilha têm por objetivo ensinar gradualmente o aluno sobre a estrutura e características do EAD. Dessa forma o conteúdo foi distribuído de modo que cada ilha possui um tópico central que ali será abordado. O CDA pode ser acessado através do link http://games.feevale.br/loa/introeadgame. Um vídeo de apresentação também está disponível em http://youtu.be/YLH3R5Xm7IY.

Na tela inicial é apresentada a interface para o login do aluno, visto que trata-se de uma CDA que será aplicado a alunos do EAD da Universidade Feevale. O jogo comunica-se com o sistema administrativo da Instituição para validar o código e a senha do aluno. Existe, também, uma versão para o público em geral cujo acesso se dá pelo usuário "visitante" e a senha "visitante".

A primeira ilha possui como objetivo explicar as mecânicas do CDA em si, ensinando os comandos de movimento e interação com objetos do cenário. Neste espaço apresenta-se, brevemente, o papel do tutor no $\mathrm{EaD}$, visto que é ele quem passa a primeira tarefa do CDA (Figura 3).

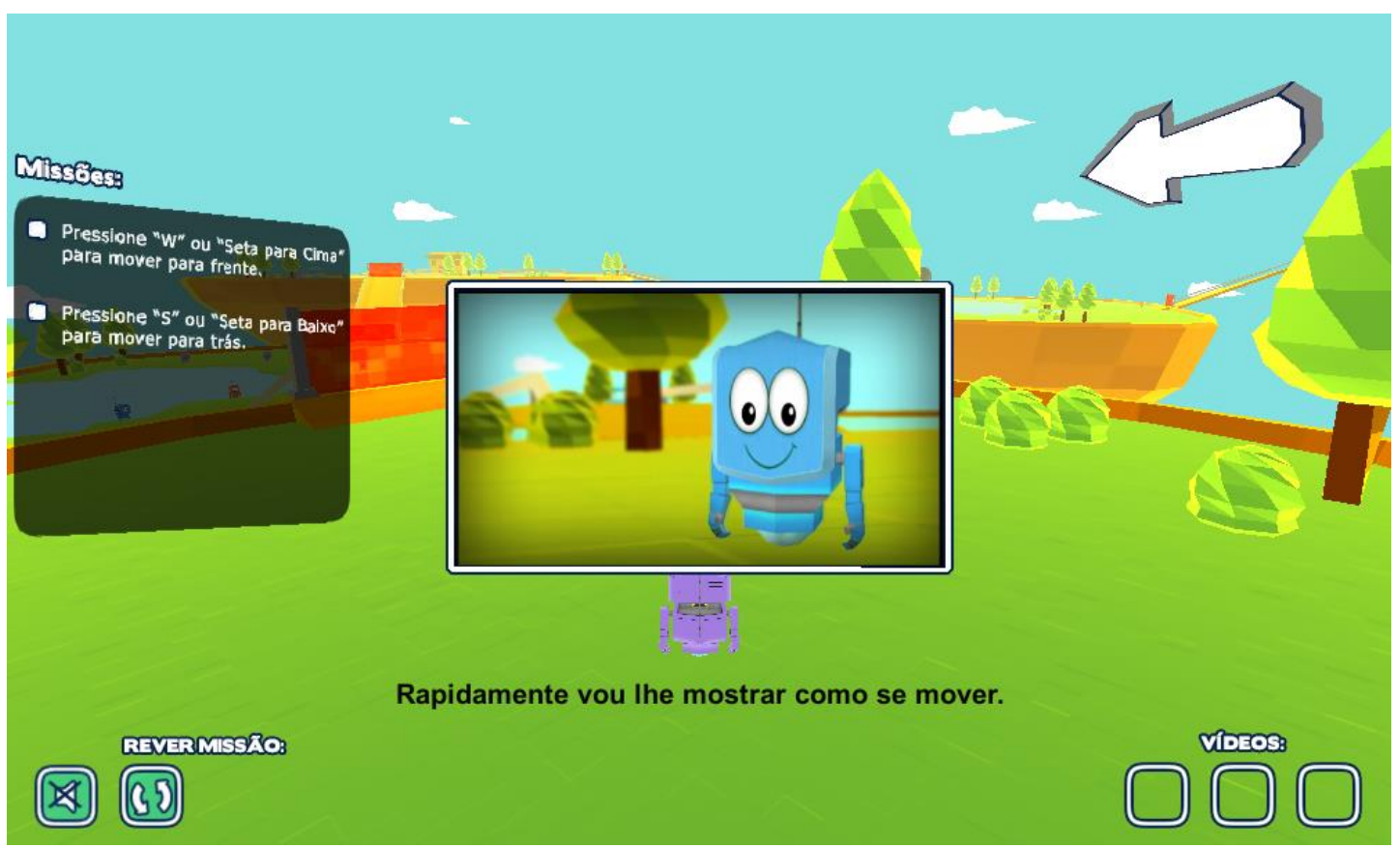

Figura 3. Primeira ilha do CDA Introdução aos estudos Virtuais.

$\mathrm{Na}$ segunda ilha são apresentados os atores existentes em um ambiente de estudo à distância, ou seja, tutores, professores e colegas de disciplina. O primeiro contato do aluno novamente ocorre com o tutor, que explica que sua função é acompanhá-lo em suas atividades, esclarecer dúvidas e orientar os alunos. Na sequência é apresentado o papel do professor, que passará a próxima tarefa ao jogador.

O tema abordado na próxima ilha é a interação entre alunos da mesma disciplina e os comportamentos esperados no espaço de ensino à distância. Para isso a tarefa passada ao jogador remete a um trabalho em equipe, onde ele desempenha um papel na 
construção do conteúdo em conjunto com seus colegas (Figura 4). Por fim, o aluno precisa responder uma questão relativa ao tema abordado, buscando, desta forma, reforçar o conteúdo visto nessa ilha antes que o acesso à próxima seja liberado.

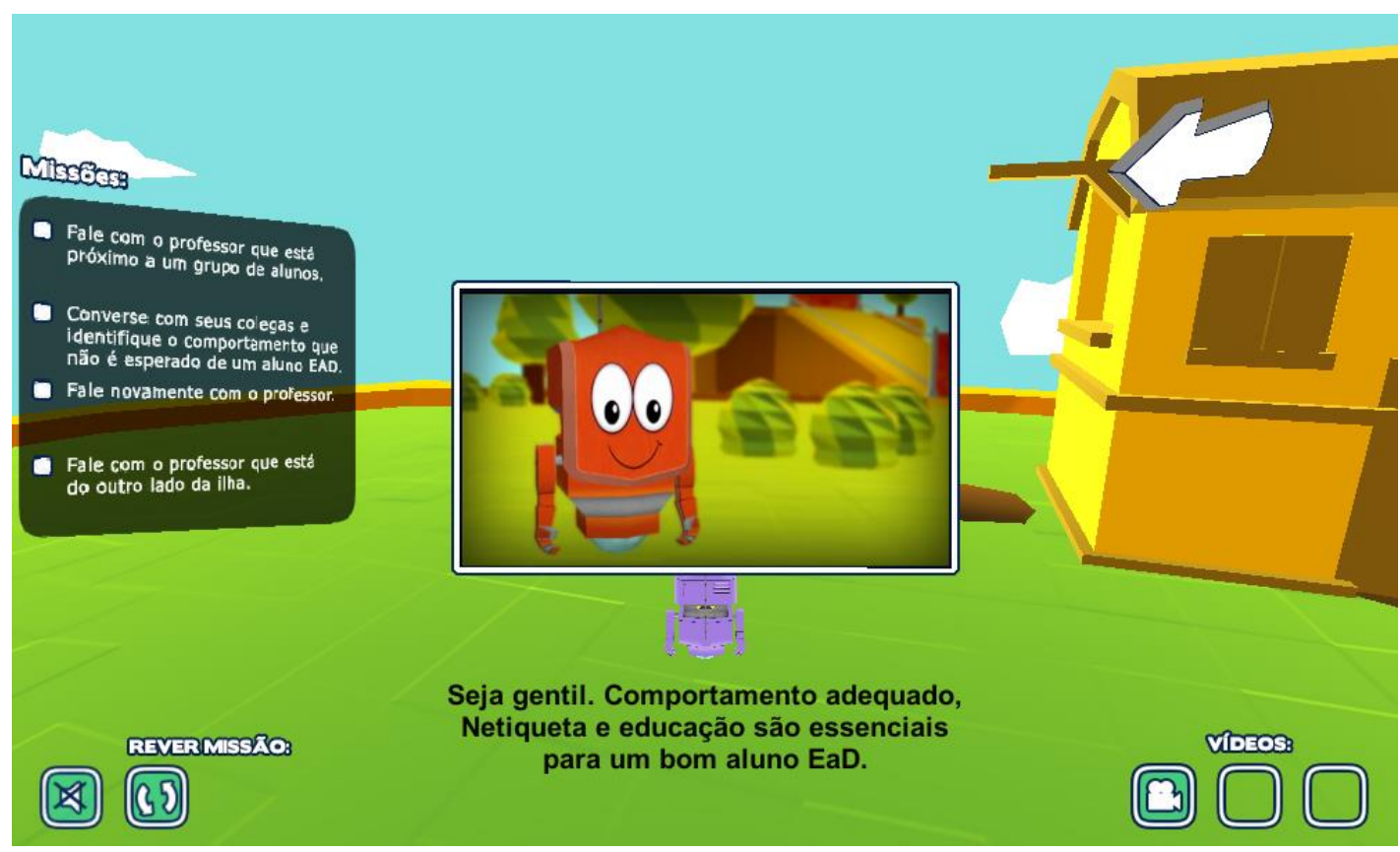

Figura 4. Terceira ilha do CDA Introdução aos Estudos Virtuais.

Na quarta e penúltima ilha existe um apanhado de todos os conteúdos, buscando uma revisão, com a primeira tarefa envolvendo interação com colegas e apresentação de resultados ao tutor. Por fim, a última tarefa tem como objetivo mostrar ao aluno as diversas ferramentas de comunicação com a universidade disponíveis

Após a conclusão de todas as tarefas o acesso à última ilha é desbloqueado. É a ilha final, onde o aluno é parabenizado pela conclusão do CDA.

\section{Resultados}

A partir do segundo semestre de 2013 o CDA "Introdução aos Estudos Virtuais" foi disponibilizado aos alunos da Universidade Feevale no ambiente virtual de aprendizagem Blackboard. O Construto poderia ser utilizado para o cumprimento de uma tarefa obrigatória a todos os alunos de cursos totalmente a distância, como uma alternativa ao método tradicional que envolve a leitura de um documento de regras e demandas de posturas virtuais. Esperou-se que o jogo fosse capaz de passar ao aluno de forma mais lúdica estas mesmas as demandas e regras oriundas de um curso de $\mathrm{EaD}$ da instituição, bem como, apresentar ao aluno um modelo de postura e netiqueta esperados dele para com os demais colegas de curso, tutores e professores no ambiente virtual.

O CDA "Introdução aos Estudos Virtuais" já foi acessado e utilizado por mais de 350 alunos da Universidade Feevale. No último levantamento realizado, do total de estudantes que utilizaram o construto, pode ser observado que $62,5 \%$ eram do sexo masculino e $37,5 \%$ do sexo feminino. Os cursos a distância que utilizaram o CDA foram: Gestão da Tecnologia da Informação, Tecnologia em Gestão Pública, Tecnologia em Logística e Tecnologia em Processos gerenciais. 


\section{CBIE-LACLO 2015}

Anais dos Workshops do IV Congresso Brasileiro de Informática na Educação (CBIE 2015)

O maior tempo para conclusão de uso do CDA foi de 54 minutos (aluno do sexo masculino, tem 52 anos e estuda em dois cursos na instituição: Curso Superior de Tecnologia em Gestão Pública e Curso Superior de Logística) e o menor de 12 minutos (sexo masculino, tem 25 anos e estuda no curso Superior de Tecnologia em Logística). A média por de tempo por aluno foi de 17 minutos.

Foi disponibilizado um fórum para que os alunos pudessem se expressar, indicando aspectos positivos e negativos referentes ao uso do CDA. No período analisado, 55 comentários foram postados no fórum, sendo duas críticas: "sem apelos para fixar o jogador" e "um pouco confuso", cada uma delas indicada por um estudante. Todas as demais avaliações foram positivas, destacando-se os aspectos referentes a "grande possibilidade de interação" (23 interações), "objetivos claros" (10 interações), "retrata o que é necessário para um aluno EAD” (20 interações), dentre outras.

Quando questionado aos alunos sobre o aprendizado gerado pelo construto digital de aprendizagem "Introdução aos estudos Virtuais", os estudantes destacaram os seguintes termos como essenciais para um aluno que estuda a distância: disciplina, iniciativa, organização, comprometimento e interação. Esses termos são os destacados no decorrer de todo o CDA, o que pode demonstrar que o uso do mesmo foi efetivo, ou seja, os alunos conseguiram compreender e apreender sobre o conteúdo estudado.

\section{Considerações Finais}

A partir do feedback obtido através dos fóruns, percebe-se uma grande aceitação por parte dos alunos do CDA "Introdução aos Estudos Virtuais". Desde o início das aplicações em 2013, houveram apenas duas críticas pontuais contra 53 avaliações positivas.

Pode-se concluir que diversos fatores contribuíram para tal resultado, como por exemplo, o cuidado com a calibragem e ajustes realizados no jogo em função das validações feitas previamente. Tal avaliação pode ser observada, por exemplo, na redução do tempo médio de término da versão final do CDA (17 minutos) em relação ao protótipo (21 minutos). Percebeu-se também que a diferença entre a média e o menor tempo de término (12 minutos) não é muito elevada, o que reforça a eficácia das melhorias implementadas. Também não foi apontada a existência de uma parede de dificuldade que perturbasse ou impedisse o término da atividade. Além disso, as palavras necessárias para um aluno $\mathrm{EaD}$, destacadas pelos estudantes, evidenciam a compreensão e absorção do conteúdo transmitido, dado que esses são os temas abordados no decorrer de todo o CDA.

Em referência aos feedbacks negativos, nota-se que, em um dos casos, o problema apontado ocorreu em função de que o jogador não se sentiu atraído pela atividade conforme relatado pelo próprio aluno. Na outra avaliação, o comentário foi de que a atividade era um pouco confusa, o que talvez possa ser um sintoma de um usuário não-nativo digital (Alves, 2008).

O CDA continua sendo aplicado na instituição, o que possibilitará a coleta de mais dados que poderão ser utilizados na melhoria do próprio jogo e desenvolvimento de projetos futuros. Além disso, a partir do segundo semestre de 2015, será utilizado um 
questionário virtual para que os alunos possam apontar aspectos positivos e negativos de determinados pontos do jogo, como da metodologia empregada, dos aspectos técnicos, sobre a linguagem, etc. Novos levantamentos serão feitos levando-se em conta os resultados destas respostas.

\section{Referências Bibliográficas}

Alves, L. R. G. (2008). "Relações entre os jogos digitais e aprendizagem: delineando percurso". Educação, Formação \& Tecnologias, v. 1, p. 3-10.

Bez, M. R., Mossmann, J. B., Mendes, T. G., Branco, M. (2012) "Projeto para Desenvolvimento de Objetos de Aprendizagem no Formato de Jogos Sérios". In: Congreso Internacional de Ambientes Virtuales de Aprendizaje Adaptativos y Accesibles, 4., 2012, Cartagena. Anais do IV Congreso Internacional de Ambientes Virtuales de Aprendizaje Adaptativos y Accesibles, Cartagena: Cava, 2012, v.1, p. 110.

Branco, M., Bez, M. R., Mossmann, J. B., Mendes, T. G. (2013) "Dimensões dos Jogos de Ensino". In: ICECE'2013 - Congresso Internacional em Educação em Engenharia e Computação, 2013, Luanda. Anais do ICECE'2013 - Congresso Internacional em Educação em Engenharia e Computação. São Paulo: COPEC, 2013. v. 1. p. 277-281.

Ericsson, K., Simon, H. (1993) "Protocol Analysis: Verbal Reports as Data". Cambridge, MA: The MIT Press.

Valadares, V. C. S., Fardin, W. J. M., Mossmann, J. B., Branco, M., Bez, M. R. Mendes, T. G. (2014). "Desenvolvimento e Aplicação do CDA Introdução aos Estudos Virtuais". Porto Alegre: Revista RENOTE. v. 12, n. 2, dezembro, 2014. 